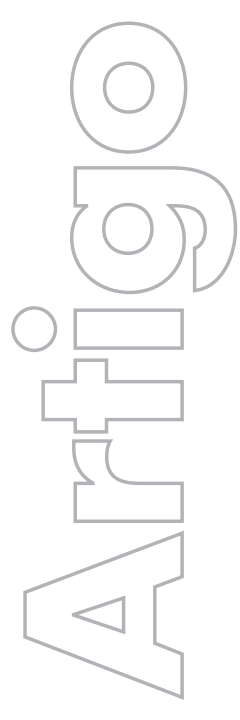

revista

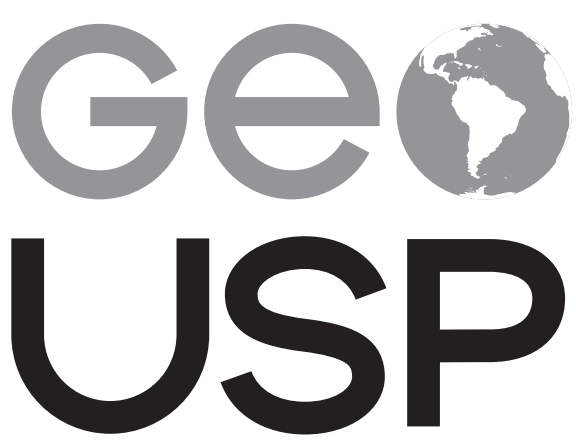

espaço e tempo

Volume $21 \cdot n^{\circ} 2$ (2017)

ISSN 2179-0892

\section{Espacialidades e} interseccionalidades na vivência de mulheres prostitutas mães na cidade de Ponta Grossa-PR

\author{
Juliana Przybysz \\ UEPG
}

p. $570-585$

Como citar este artigo:

PRZYBYSZ, J.; SILVA, J. M. Espacialidades e interseccionalidades na vivência de mulheres prostitutas mães na cidade de Ponta Grossa-PR. Geousp - Espaço e Tempo (Online), v. 21, n. 2, p. 570-585, agosto. 2017. ISSN 2179-0892.

Disponível em: < http://www.revistas.usp.br/geousp/ article/view/117719>. doi: 10.11606/issn.2179-0892. geousp.2017.117719.

\section{(c) $(1)(9)$}

Este artigo está licenciado sob a Creative Commons Attribution 4.0 License. 


\title{
Espacialidades e interseccionalidades na vivência de mulheres prostitutas mães na cidade de Ponta Grossa-PR
}

\section{Resumo}

Este artigo visa compreender como a interseccionalidade entre maternidade/ maternagem e prostituição feminina de baixa renda constituem espacialidades na cidade de Ponta Grossa-PR. A partir do desempenho de papéis sociais tidos como opostos - o de mãe, associado ao amor, e o de prostituta, associado ao pecado -, entendemos que as espacialidades vividas pelas mulheres mães prostitutas transpassam esses paradoxos a partir da interseccionalidade. As experiências sociais dessas mulheres são vistas como práticas encaixadas construídas por e através do espaço. A concomitância dos dois papéis faz com que essas mulheres criem estratégias espaciais para desenvolver a prostituição e a maternidade/maternagem.

Palavras-chave: Espacialidades. Gênero. Prostituição. Interseccionalidades. Maternagem.

\section{Spatiality and intersectionality in the experience of prostitute women who are mothers in the city of Ponta Grossa, Paraná}

\begin{abstract}
This paper aims to understand how intersectionality between motherhood/ maternity and low income female prostitution compose spatiality in the city of Ponta Grossa, Paraná. Through the performance of social roles conceived as opposed to mothering that are associated to love, prostitution and sin, it is possible to understand that spatiality lived by mothers prostitutes women go through these paradoxes from the intersectionality. Social experiences of these women are seen as embodied practices built by and through space. The experience of both roles makes these women create spatial strategies to developing prostitution and motherhood/ maternity.
\end{abstract}

Keywords: Spatiality. Gender. Prostitution. Intersectionality. Maternities. 


\section{Introdução}

$\bigcirc$ objetivo deste trabalho é compreender como a interseccionalidade entre maternidade/maternagem e prostituição feminina de baixa renda constituem espacialidades na cidade de Ponta Grossa, Paraná. Este texto leva em consideração a construção paradoxal dos papéis de mãe e de prostituta e o tensionamento social em relação ao gênero e a sexualidades no exercício de ambos os papéis. A impossibilidade de coexistência destes papéis constitui-se naquilo que Duncan (1996) denomina como marginalização espacial das trabalhadoras do sexo, pois a prática da prostituição ofende a sociedade, colocando em ameaça as noções daqueles comportamentos que são considerados aceitáveis. É devido a isto que fica reservada a esta atividade uma temporalidade/espacialidade específica, excluindo-se a possibilidade da relação entre esta atividade e a da maternagem.

A experiência de vivenciar ambos os papéis em uma sociedade que renega a condição de mãe e prostituta faz com que estas mulheres criem estratégias espaciais que permitem desenvolvimento da prostituição e maternagens. Levando em consideração as modalidades abertas, prostituição de rua e fechadas, prostituição de bar e boate, na cidade de Ponta Grossa encontramos em cada um desses tipos especificidades em relação a essas experiências. A situação de vulnerabilidade econômica que também é um componente interseccional das experiências destas mulheres dificulta a separação entre o espaço de execução da prostituição e o espaço em que executa o papel como mãe.

Para compreender as espacialidades de mulheres prostitutas mães, foram levantados dados a partir de observação em campo, questionários fechados e entrevistas semiestruturadas realizadas com mulheres prostitutas mães. Os dados evidenciam que estas mulheres jogam com os papéis de mãe e profissionais do sexo, tirando proveito de sua condição materna, muitas vezes a invisibilizada devido à atividade, mas que permite o sustento dos filhos.

Este texto está estruturado em duas partes. Na primeira são discutidos os conceitos que buscam dar inteligibilidade ao fenômeno. Na segunda, a partir dos 95 questionários fechados e doze entrevistas feitas com mulheres prostitutas mães nos três tipos de prostituição, evidenciamos os elementos que estruturam as práticas de prostituição, maternagens e as espacialidades, determinantes para a manutenção destes papéis.

\section{Prostituição e maternagem/maternidade: uma perspectiva interseccional}

Compreender a opressão vivenciada e as estratégias criadas por mulheres prostitutas mães a partir da interseccionalidade remonta a construção social do que é ser mulher, que está baseada em papéis e comportamentos que têm sido naturalizados ao longo do tempo. Essa naturalização cria uma categoria chamada "mulheres" e não leva em consideração as experiências únicas vivenciadas por meio da constituição interseccional de diversas identidades. Butler (2003) argumenta que não há uma única identidade feminina que possa abrigar todas as diferenças existentes na vida cotidiana. Para a autora, o termo "mulheres" denota algo comum, colocando-as com iguais sem distinção de raça, classe, sexo, entre outras categorias. As normas ligadas à binaridade homem/mulher reforçam uma identidade feminina única e a manutenção de comportamentos considerados "normais" que estão baseados em práticas sociais que compõe o mecanismo de gênero. 
Essas práticas sociais estão relacionadas à familia, ao casamento, ao amor, à maternidade, à maternagem, entre outros. Cada uma, a seu modo constrói papéis destinados às mulheres e aos homens, de forma diferenciada para cada um, separando o que é ser homem do que é ser mulher, reforçando o mecanismo de gênero. Esta separação entre os papéis, segundo Laqueur (2001), teve início no século XIII a partir das diferenças corporais que não ficaram só nos corpos biológicos, mas resultaram em diferenças sociais e psicológicas e que só tiveram início quando se "tornaram politicamente importantes" (Laqueur, 2001, p. 21).

Do isomorfismo ao dimorfismo, as mudanças foram resultado de um desenvolvimento epistemológico, ligado à biologia, e político, ligado às novas formas de pensar os sujeitos e realidades sociais, sendo reforçada pela religião, iluminismo, Revolução Francesa, conservadorismo e divisão sexual do trabalho (Laqueur, 2001). Para Johnston (2005) a dualidade homem/mulher teve início com a filosofia, quando a masculinidade foi associada a razão, a mente e abstração, e a feminilidade a irracionalidade, o corpo e materialidade. Assim, a história da humanidade foi constituída reforçando essa separação tão subjetiva das relações de gênero e sexualidade, fundamentada em uma heteronormatividade e divisão de papéis.

$\bigcirc$ binário homem/mulher tornou-se uma verdade e tem sido considerado como universal e natural, sem levar em conta as relações de espaço, lugar, tempo e culturas. Se os corpos são pensados como naturais e dicotomizados em sexo feminino e masculino, estas mesmas normas dicotômicas são interiorizadas e criam novas dicotomias, tais quais J. Silva et al. (2013, p. 92) aponta: "público/privado, sagrado/profano, produção econômica/reprodução familiar, local/global e assim por diante". Essa construção social binária coloca a profissional do sexo como independente da mãe, pois a primeira não está em conformidade com a castidade do casamento, sexualidade privada, cuidado com os filhos e ao espaço privado, excluindo-as das relações homem/mulher e mulher/mulher por não seguirem os "padrões" sociais. Assim, compreender as práticas sociais que reforçam o mecanismo de gênero é compreender as estruturas que marginalizam e excluem estas mulheres.

Uma prática que reforça o mecanismo de gênero é a constituição de família. Para Engels (1982), a família ocidental monogâmica foi estabelecida pelo Estado que a partir do parentesco visava o aumento da produtividade do trabalho e da manutenção da propriedade privada. Para ele, quando o direito a filiação passa a ser do homem e não mais da mulher, como na poliandria, estas têm uma derrota histórica, pois passam a ser propriedade masculina e instrumento de procriação. A família burguesa torna-se um padrão que assegura a fidelidade feminina e a família, agora patriarcal, relega as mulheres ao papel de mãe, de reprodução e da sexualidade privada e ao homem cabe a infidelidade e a produção do lar.

Para Rago (1985) no Brasil do século XIX a família era uma imposição, um modelo criado pela burguesia para domesticar o trabalhador, a fim de acabar com a promiscuidade, fortemente relacionada à classe trabalhadora. Surge um novo modelo de mulher, com novas formas de comportamento e de etiqueta, forjada em um modelo ideal de esposa e dona de casa, amável e assexuada. A construção social da família colocou a mulher como periférica nas relações de poder e reforçou as dicotomias entre homens e mulheres. Esse modelo de família coloca as mulheres prostitutas mães em situação periférica, pois não seguem os "padrões" relacionados à sexualidade, separando-as das "boas" mulheres. 
Além da familia, a própria maternidade/maternagem repercute na organização e em práticas sociais que tornam a mulher sinônimo de natureza, amor, passividade e submissão, devendo ter um bom ventre, bons filhos e ser cuidadora da familia. Para Badinter (2011) a função de cuidadora está relacionada ao "instinto materno" que relega as mulheres a marginalidade em relação a outras identidades, pois antes de tudo são mães, para depois mulheres, trabalhadoras, estudantes etc.

Entretanto, para esta autora não existe um instinto materno e sim uma construção do amor entre mães e filhos, ao que ela chama de maternagem. A ideia de que todas as mulheres nascem para serem mães nada mais é do que construir um papel de gênero arraigado à mulher. É nesse sentido que Longhurst (2008) argumenta que maternidade e a maternagem são coisas distintas, em que a primeira é uma experiência natural e a segunda é um complexo fenômeno social e tanto uma quanto a outra são produzidas diferentemente em diferentes lugares e são indissociáveis de corpo, gênero, lugar e cultura.

Para Badinter (2011), a maternidade/maternagem reforça as relações dicotômicas homem/mulher, devendo ser pensadas como uma realização de vida e não um destino obrigatório. A identidade materna como um instinto natural aumenta as desigualdades, já que a paternagem não vem sendo desconsiderada ao longo dos anos. Entretanto, quando estas mulheres mães são prostitutas há uma reconfiguração nos papéis onde, a maternidade e a maternagem são esquecidas e negadas devido à atividade profissional, pois é como se a prostituição a desqualificassem como mães, tornando essas identidades desalinhadas.

A familia e a maternidade/maternagem como um dever social para as mulheres são reguladas pelo casamento, priorizando um bom andamento social e a regulação dos papéis de homens e mulheres e principalmente a sexualidade feminina. Para Catonné (2001) a partir da inserção social do cristianismo, o casamento torna-se uma forma de canalizar os desejos, a atividade sexual, a sexualidade e o erotismo, sendo uma das principais formas de regulação e da divisão dos papéis de homens e mulheres.

Segundo Rougemont (2003) o sacramento do casamento passa a ser a única opção para a atividade sexual, que tem apenas a intenção de procriação e o amor seria uma condição para o acontecimento casamento, mesmo que este nunca tenha sido visto em nenhum evangelho. A ideia de casamento como um sacramento reforçou a ideia de uma sexualidade privada, de cuidados com os filhos e marido, excluindo as mulheres do espaço público. A sexualidade torna-se velada e, se exacerbada, a mulher passa a ser reconhecida como "puta" ou "prostituta", reforçando os padrões de "boa" e "má" mulher. Para Juliano (2004) há uma força tão grande em relação a esse modelo da má mulher - a puta - e da "boa" mulher que o resultado é o esquecimento, invisibilidade e rechaço as mulheres que se utilizam da prostituição.

Levando em consideração os comportamentos McDowell (1999) argumenta que estes têm sido apropriados, interiorizados, refletidos e esperados socialmente tornando-se um reflexo da dicotomia homem/mulher e reforçado por práticas sociais. Para a autora esta binaridade implica na produção social do espaço a partir da construção de conjuntos de normas, que tem efeito de excluir e marginalizar socioespacialmente a mulher impedindo-as de vivenciar determinadas espacialidades. 
Assim, o espaço vem sendo uma categoria importante para a compreensão de gênero e sexualidade, principalmente quando pensado como um movimento constante de relações sociais. Massey (2008) ao fazer uma crítica às concepções de fixidez do espaço argumenta que este é aberto, vivido e heterogêneo e que deve ser visto como inter-relacional, ou seja, práticas encaixadas que não são colocadas como entidades/identidades já constituídas, mas construídas por e através do espaço, assim como, o espaço sendo construído por e a partir de identidades relacionais, tudo isso constituído a partir de negociações internas e espaciais, ou seja, políticas. Para a autora, o espaço múltiplo, em construção e uma composição de estórias até agora, deve ser compreendido por meio das espacialidades, em que esta não é reduzida a uma simples ficção, mas incorpora a realidade vivenciada pelas pessoas, incluindo as relações entre gênero e sexualidade, em que o espaço é o próprio ser transcendendo as noções de estruturalismo.

A construção e práticas sociais relacionadas à familia, ao casamento e à maternidade/ maternagem reforçam normas de gênero produzindo e reproduzindo espacialidades. $\bigcirc$ gênero para Scott (1995) tem duas partes e muitos subconjuntos, são elas: "(1) o gênero é um elemento constitutivo de relações sociais baseadas nas diferenças percebidas entre os sexos e (2) o gênero é uma forma primária de dar significado às relações de poder" (Scott, 1995, p. 86). Os significados de gênero imbricados nos corpos das prostitutas criam uma dicotomia entre a "boa" e a "má" mulher.

Para Butler (2003) o gênero produz uma falsa noção de estabilidade dos corpos e dos papéis, a partir de uma matriz heterossexual. Desconstruindo a ideia de linearidade entre as categorias sexo/gênero/desejo, para a autora: "o gênero é a estilização repetida do corpo, um conjunto de atos repetidos no interior de uma estrutura reguladora altamente rígida, a qual se cristaliza no tempo para produzir a aparência de uma substância, de uma classe natural do ser." (Butler, p. 59). Seguindo as proposições de Butler, para J. M. Silva (2009) a partir do conceito de espaço, o gênero:

[...] não é uma realidade em si mesma, mas um ideal exercitado cotidianamente por diferentes tipos de corpos que, ao agirem pautados pela representação, superam a mera reprodução de papéis e recriam continuamente a própria representação de gênero. Assim, o gênero é um eterno movimento que se faz na ação humana criativa, e como toda ação implica uma espacialidade, o caráter performático do gênero é simultaneamente espacial e temporal (Silva, J. M., 2009, p. 84).

A partir da concepção de gênero como uma norma, compreendemos que as mulheres que escapam desta "normalidade" são consideradas prostitutas, putas, desviadas e ligadas ao mau. Essa divisão entre a "boa" mulher e a "má" mulher gera novos tipos de dicotomias, cujo estigma da má mulher serve para regular os corpos das "boas" mulheres (Juliano, 2005).

Para Duncan (1996) a prostituição reconhecida como suja traz às pessoas que utilizam esta atividade como fonte de sobrevivência uma série de embates sociais devido ao estigma, mas que a prostituição também tem perturbado o lugar das coisas, ameaçando a respeitabilidade e o ordenamento feminino, pois estas mulheres tornam-se públicas, conse- 
quentemente não respeitadas. As prostitutas constituem uma identidade sexual chave para compreender as questões sobre os limites da heterossexualidade, pois tem suportado o seu peso simbólico, sendo constantemente impedidas de serem compreendidas a partir de uma cidadania heterossexual. Assim, a identificação da prostituta como imoral, define o que é a moral da heterossexualidade e da família, em que a imoralidade (mulher pública) e moralidade (mulher privada) são construídas espacialmente.

Para Juliano (2005), a estigmatização das prostitutas é um mecanismo eficaz para controlar as mulheres não estigmatizadas e impedi-las de infligir os modelos vigentes, cumprindo seus deveres "naturalizados" como parte de suas características de gênero. Seguindo as normas de gênero o trabalho sexual é o setor que mais carrega estigma social, pois há uma compreensão de que a sexualidade é algo que não se vende e que deve ser dado sem pedir algo em troca.

Compreender a espacialidade de mulheres prostitutas mães e o tensionamento provocado pela vivência espacial destas duas identidades dicotômicas desconstrói as normas vigentes de gênero. Essas identidades não são únicas, são múltiplas e vividas de forma interseccional, não são destacadas ou esquecidas em determinadas espacialidades, mas são gerenciadas para fugir da opressão ou tirar proveito desta intersecção. As identidades, segundo Hall (2011), são fluídas, contraditórias, estão sempre em construção, nunca acabam em si mesmas, são fragmentadas a partir da vivência e experiência de cada um e são formadas e reformadas a partir das representações que temos do mundo.

Para Pulido (1997), a vivência de pessoas em determinados lugares desenvolvem identidades baseadas nestes mesmos lugares e não são estáticas, unitárias, são múltiplas e mutáveis e também formam o lugar, (re)produzindo espaços. É nesse sentido que J. Silva e M. Silva (2014) argumentam que significados, tensões e relações de poder produzidos pelos diferentes sujeitos sociais têm introduzido na geografia brasileira as discussões sobre o conceito de identidade e tem permitido a superação da ideia de binaridade, em que a possibilidade não para em uma ou em outra identidade construída espaçotemporalmente e sim nas mais variadas facetas identitárias que estão sempre em negociação e articulação.

A partir dessa concepção, J. Silva e M. Silva (2014) trazem à tona o conceito de interseccionalidade, que tem início com o feminismo negro, em que a experiência espacial das mutheres negras era diferente das mulheres brancas devido aos contextos e traços próprios permeados pelo sexismo e racismo, gerando diferentes tipos de marginalizações não reconhecidos pelo movimento feminista branco. Surge, então, a compreensão de que há diferentes privilégios levando em consideração a raça e a classe, construindo um fértil caminho de pensamento em relação à interseccionalidade e os sistemas de opressão.

Crenshaw (1991) argumenta que políticas identitárias têm esquecido as diferenças, reconhecem os diferentes grupos, mas ignoram que a violência acontece devido a outros eixos identitários. A partir de uma pesquisa em uma casa de acolhida de mulheres que passaram por violência em Los Angeles, a autora argumenta que as diversas formas em que raça, classe e o gênero se cruzam, na vivência dessas mulheres dão lugar a aspectos estruturais e políticos próprios, que são desconsiderados. Segundo ela, cada eixo identitário ao se cruzar cria intersec- 
ções que complexificam a experiência pessoal, pois cada categoria expressa relações de poder que de alguma forma é exercido contra outras categorias, tendo consequências diferentes para cada um. Assim, a interseccionalidade é uma articulação de eixos identitários que dão base às desigualdades sociais e reforçam estruturas de poder, gerando posições relativas em determinados espaços e tempo.

Para McCall (2005), o conceito de interseccionalidade não pode ser compreendido a partir das identidades como algo anterior às relações sociais experienciadas, pois a complexidade dessas relações identitárias deriva de diferentes contextos sociais revelando diferentes desigualdades. Nesse sentido, argumenta que categorias gerais como gênero, sexualidade, classe, raça, não dão conta das dimensões contraditórias que envolvem a experiência em relação a estruturas mais complexas e contraditórias.

A vivência espacial de mulheres prostitutas mães pobres é uma complexidade das estruturas de gênero e sexualidade e não pode ser compreendida apenas a partir desses eixos gerais. Seguindo as proposições de McCall (2005), compreendemos que a maternidade/maternagem, casamento, amor, prostituição e família compõem as categorias de gênero e sexualidade, mas antes, são o próprio cotidiano, a experiência e as relações sociais dessas mulheres. A composição destes cruzamentos está relacionada ao poder e à opressão, mas também à resistência, aos conflitos e ao proveito dessas intersecções (McCall, 2005). A construção e reconstrução das identidades das profissionais do sexo mães pobres está relacionada aos sistemas de opressão, poder, que geram resistência, conflito e proveito de determinadas situações, tornando o conceito de interseccionalidade um forte aliado na compreensão das espacialidades vividas por estas mulheres.

Para Valentine (2007), as diferentes identidades podem ser mais evidentes em determinados espaços que em outros, e esse movimento identitário está relacionado com as vivências e experiências espaciais, permitindo um jogo interseccional identitário. Sendo as identidades "feitas" espacialmente, para a autora devemos buscar compreender como a interseccionalidade é produzida espacialmente, como determinados elementos da intersecção podem ser oprimidos em determinadas espacialidades e valorizados em outras.

Esse movimento de identidades a partir das diferentes espacialidades pode ser visto a partir das categorias gerais como gênero, classe, sexualidade, raça (Valentine, 2007), mas também fica evidente quando é pensado a partir de intracategorias (McCall, 2005) trazendo o conceito de interseccionalidade mais perto da realidade. Por isso, compreender vivências espaciais de mulheres prostitutas mães pobres a partir do conceito de interseccionalidades traz à tona identidades contraditórias de mãe e de prostituta criado a partir da dicotomia homem/ mulher e mulher/mulher, ou seja, das normas de gênero e sexualidade, construindo identidades que são vistas como marginais e centrais.

A prostituição vista como uma ferramenta de regulação dos corpos para a produção de "boas" mulheres estigmatiza as prostitutas e dicotomiza este papel com o de mãe. Entretanto estas duas identidades são reconhecidas pelas prostitutas mães, que desenvolvem estratégias de resistência, subvertendo as situações de opressão e de poder, em que o espaço passa de uma mera abstração para um agente que constrói as relações que são vividas por essas mulheres. 


\section{Opressão, poder, resistências e estratégias: a intersecção entre prostitui- ção e maternidade/maternagem}

A cidade de Ponta Grossa é considerada um entrocamento rodoferroviário (Prefeitura [...], [s.d.]), sendo propícia para o desenvolvimento da prostituição, já que é uma passagem importante para a região sudoeste e sul do Brasil e próxima ao Porto de Paranaguá, além de ter uma forte presença industrial e de universidades, se caracterizando por um grande fluxo de carros, caminhões e pessoas. Para Jan C. Silva (2011), esse fluxo intenso é um atrativo para a prostituição já que sua concentração está relacionada a lugares de segregação residencial, fluxo de pessoas e econômicos, zonas comerciais, rodovias etc. Existem quatro tipos de prostituição na cidade: de rua, de bar, de boate e de cyberespaço.' A prostituição de rua, bar e boate estão relacionadas ao que Jan C. Silva (2011) chama de modalidades da prostituição, modalidade aberta, relacionada à rua e à fechada incluindo bares e boates. Esta configuração evidencia que cada tipo de prostituição desencadeia processos espaciais e vivências diferenciadas pelas profissionais do sexo.

Para Hubbard (1999) a dinâmica da prostituição na contemporaneidade deve ser compreendida a partir das espacialidades de poder, repulsa e desejo, já que faz parte do espaço urbano a partir da oferta de encontros de desejo e ao mesmo tempo de regulação e distribuição das populações que vivem da sexualidade. $\bigcirc$ autor ainda argumenta que os geógrafos também devem compreender os espaços de prostituição a partir da construção social de identidades de prostitutas e de clientes.

Para compreender as construções identitárias das mulheres prostitutas mães em Ponta Grossa, como aponta o geógrafo Phill Hubbard (1999), faz-se necessário compreender a própria constituição da prostituição na cidade que conta atualmente com 75 pontos de prostituição feminina e travesti, ${ }^{2}$ sendo $48 \%$ referente à prostituição de rua, $48 \%$ de bar e $3 \%$ em boates. A prostituição feminina de boate é considerada de alto poder aquisitivo para Ponta Grossa e se configura como espaços de sensualidade e prazer, sendo pensada para chamar a atenção do cliente, indo desde a disposição dos móveis até as cores, bebidas e shows. As boates se configuram pela descrição e segurança, investem na invisibilidade do cliente e da profissional, pois se encontram em locais segregados. As profissionais geralmente moram na boate, são de fora da cidade ${ }^{3}$ e preferem o anonimato.

Diferente das boates, os bares dão maior visibilidade as profissionais, são menores, não tem características de espaços para o prazer ${ }^{4}$ e estão localizados no centro (maior concentração), bairros e rodovias da cidade. As características que diferem de um bar convencional é a própria presença feminina, refletindo a organização binária no espaço (McDowell, 1999), pois o bar não seria um lugar de "boas" mulheres, tornando a própria presença feminina um indicativo da prostituição. Além da presença feminina, há biombos em frente aos bares bloqueando quase

\footnotetext{
1 Apenas os três primeiros tipos de prostituição foram objeto deste estudo.

2 Embora a prostituição travesti não seja o foco deste trabalho, destacamos a sua importância na prostituição feminina, já que por questões de segurança estão sempre juntas.

3 Informação baseada em gerentes de boates, profissionais do sexo e observação de campo.

4 Os espaços de prazer estão relacionados ao ambiente e não ao estímulo individual.
} 
toda a entrada, sendo esta uma estratégia para que as mulheres e os clientes não sejam vistos da rua. São frequentados pela classe trabalhadora e baixa e a maioria abre no período diurno, horário este associado ao exercício de maternagens e disponibilidade do cliente.

A prostituição de rua, em sua maioria também é diurna, sendo desenvolvida no centro da cidade e em dois pontos de rodovias que cortam a cidade. A diferença é que, na prostituição aberta, a exposição dos corpos femininos é maior, aumentando o preconceito, mas também torna a mulher independente financeiramente, pois não tem que pagar o quarto ou beber para assegurar a clientela. Cada mulher elege o lugar de acordo com suas necessidades e suas relações socioespaciais no espaço privado, bairro e nos locais de prostituição. Os locais de prostituição são centrais na vida privada (cuidado com os filhos) e pública e a rua, o bar e a boate, tornam-se uma extensão da casa e simbolizam pertencimento. Entretanto, as relações que envolvem o cotidiano, desde o sustento dos filhos até as relações sociais nos locais de prostituição não são levadas em consideração, mas apenas o corpo na esquina.

Para Juliano (2005) não há como julgar a prostituição sem conhecer a realidade destas mulheres, suas práticas sociais e experiências. Levando em consideração a aplicação de 114 questionários fechados nos três tipos de prostituição, observamos que 82,4\% das profissionais são mães e a prática social da maternidade e maternagem é central em suas vidas e é esta condição, na grande maioria dos casos, que as leva a prostituição.

A prostituição como uma forma de sustento também é composta por outras práticas sociais e identidades dando corpo a interseccionalidade. Um componente desta intersecção, junto com a maternidade/maternagem, é o estado civil. Do total de mulheres prostitutas mães, $72 \%$ são solteiras, $10 \%$ divorciadas e $2 \%$ viúvas e criam sozinhas os filhos. Segundo Badinter (2011) sendo o papel de mãe considerado um instinto natural e intrínseco à mulher os filhos tornam-se da mãe, como aponta Lupae: "desde que eu tinha 29 anos, que eu separei do pai deles. Daí fui pro bar, porque meu ex-marido sumiu. Saiu e me deixou cheia de [...]. Não tinha dinheiro nem pra pagar luz e água, nada". ${ }^{5}$

$\bigcirc$ estado civil dessas mulheres compõe sua experiência de modo diferencial, pois para $16 \%$ do grupo a condição de mulher casada as deixa numa pequena vantagem, pois os maridos ajudam na criação dos filhos. Entretanto, o casamento é desvantagem no próprio exercício da prostituição cujo código "[...] o marido eu escondo, mas os filhos, não" ${ }^{\circ}$ está sempre presente na prostituição.

A maternidade/maternagem, o estado civil, somados a escolaridade intensificam as experiências vividas pelas prostitutas mães, principalmente em relação à classe. Levando em consideração que $27 \%$ tem ensino fundamental incompleto, $20 \%$ ensino fundamental completo, 33\% ensino médio incompleto, 17\% Ensino Médio completo e 3\% tem graduação incompleta, percebemos que a baixa escolaridade é um fator para a escolha da prostituição. Com a baixa escolaridade percebemos que $67 \%$ das mulheres prostitutas mães, tinham emprego antes de entrar na prostituição, mas que estavam ligados a atividades de diarista, auxiliar de cozinha, empregada doméstica, entre outros, que são desvalorizados socialmente.

5 Entrevista com Lupae, em 10 de julho de 2014, num bar. Na transcrição das entrevistas, preservou-se o tom oral.

6 Entrevista com Gabriela em 19 de abril de 2014, numa rua. 
Devido à necessidade de manutenção dos filhos, produção e reprodução do lar estas mulheres escolhem a prostituição pela alta rentabilidade em relação a outras atividades. Moraes (1995) argumenta que a baixa escolaridade é um elemento negativo em relação à qualificação para o mercado de trabalho e que por isso a escolha da prostituição é destino para algumas mulheres. Mesmo que esta seja a realidade de muitas mulheres brasileiras, o que distingue entre estas e aquelas é a prostituição e essa distinção só existe pelo estigma dado a atividade.

Segundo Juliano (2005), o que gera renda é a emoção, desejo e o prazer dado ao cliente, sendo a possibilidade de sustento um atrativo à manutenção da atividade. $\bigcirc$ tempo de permanência na atividade é dado a partir do cruzamento entre idade e tempo na prostituição, em que 47\% das mulheres iniciaram na prostituição entre 10 e 20 anos, ${ }^{7} 36 \%$ entre 21 e 30 anos, 14\% a partir dos 31 anos. ${ }^{8} \bigcirc$ tempo de permanência na prostituição varia em: $50 \%$ entre 0 e 3 anos na prostituição, 20\% entre 4 e 7 anos e $27 \%$ a mais de 8 anos. ${ }^{9}$ Ao cruzarmos a idade de início e o tempo na prostituição percebemos que a maioria das mulheres exercem a atividade há tempos. Em observações no campo de pesquisa, muitas mulheres mães argumentaram que não vale a pena financeiramente sair da prostituição, se saem é porque se casam, mas voltam quando se separam ou quando ficam sem dinheiro.

A escolha da atividade é para sustentar a si e à familia, o que não é diferente de qualquer outra pessoa, a não ser pelo distanciamento das normas de gênero e pelo fato de que o estigma da atividade sela essa diferença tornando-as mulheres incapazes de criar os filhos e de cuidar da familia. Entretanto a maternidade/maternagem está intimamente relacionada à prostituição, como aponta Madame Z: "Eu tive meu primeiro filho, né? Meu pai morreu, ele era bem de vida, e nós começamos a passar fome [...] tem que se virar de algum jeito. Daí, comecei a ir pra boate".10

É fato que a filiação é um fator importante, pois dos 114 questionários, 94 mulheres são mães e nessa relação existem 217 filhos, uma média de 2,3 filhos, sem levar em conta as cinco mulheres grávidas na época do levantamento dos dados. Esses filhos são de casamentos ou relacionamentos findados e muitos desses estão relacionados à própria prostituição a partir do "resgate". Com o relacionamento fixo essas mulheres engravidam e com o fim retornam à prostituição, como evidencia Ana Bolena: "e o que me dá de comer foi um programa que eu fiz, e o homem pego e me [...] não tinha filho, pegou e casou comigo, morreu e me deixou a pensão"."

Independentemente se são ou não filhos da prostituição, é fato a presença da maternagem, tornando as experiências espaciais diferente de mulheres prostitutas não mães. A idade dos filhos aponta a demanda de cuidados, em que 64\% têm de 0 a 13 anos, 14\% de 14 a 17 anos e $22 \%$ estão acima de dezoito anos. É interessante destacar que a idade dos filhos é determinante na vida das prostitutas mães, pois os menores de 13 anos ainda não sabem como vem o sustento da casa. A partir desta idade já começam a entender a situação gerando certo constrangimento a mãe como aponta Bustuariae:

\footnotetext{
7 Apesar de esse dado revelar que a prostituição fez parte da vida de mulheres menores de idade, não nos cabe aqui discutir a questão da maioridade e a escolha da prostituição.

$83 \%$ das mulheres não responderam a essa pergunta.

$93 \%$ das mulheres não responderam a essa pergunta.

10 Entrevista com Madame Z, em 5 de novembro de 2013, num bar.

11 Entrevista com Ana Bolena, em 5 de novembro de 2013, num bar.
} 
Daí foi um inocente e me conta pro meu piá mais velho né, o que eu era e o que eu deixava de ser, daí na quinta feira cheguei chorando aqui, porque eu não queria que ele soubesse [...] é que nem eu falei pra ele independente do que a mãe é ou deixa de ser, um tênis que você coloca, um computador que a mãe compra ou alguma coisa que você quer a mãe dá, o que os outros pensam ou deixam de pensar ou que falam pros outros o que eu sou, você não tem que [...] você tem que ver o que você veste, o que eu coloco no teu corpo. ${ }^{12}$

A permanência da atividade em segredo é importante, mesmo que os filhos já saibam sobre o exercício da prostituição o silêncio predomina na fase da adolescência. Os filhos maiores de idade tendem a aceitar, Madame $Z$, argumenta que seu filho mesmo ministro da Igreja, nunca falou de sua atividade, pois foi daí que saiu o seu sustento. Mesmo que a prostituição auxilie no sustento estas mulheres alegam dificuldades em revelar sua atividade devido ao estigma fazendo com que muitas deixem de morar com os filhos para que não sofram preconceito pela atividade da mãe, como é o caso de 39\% delas. Para estas mulheres também é difícil conciliar a vida de mãe e de prostituta, deixando seus filhos com as avós, pai, padrinhos, irmãs ou com as mães-babás. Já 61\% mantêm os filhos morando junto de si, acreditando que eles entenderão a forma de sustento e tendem a usar as redes de pessoalidade para não deixa-los sozinhos em casa.

A prostituição tem sido vista como fonte de sustento econômico dos filhos em $89 \%$ dos casos e mesmo no universo de prostitutas mães que não vivem com os filhos $72 \%$ continuam sustentando os filhos a partir da prostituição. Assim, mesmo não sendo aceita socialmente o dinheiro é bem-vindo, neste sentido a maternagem está presente na prostituição, assim como a prostituição é presente no desenvolvimento de maternagens. As espacialidades da prostituição de bar, boate e rua têm implicações diferenciadas na construção de maternidade/maternagem, pois algumas prostitutas mães escolhem a invisibilidade, outras a autonomia, enquanto algumas acreditam que não há como se esconder. Cada tipo constitui espaços de constante resistência e vigilância em relação aos filhos, fazendo com que cada mulher desenvolva estratégias diferenciadas.

As mulheres que exercem a prostituição em boates moram no mesmo lugar, complexificando as relações entre a atividade e maternagens. As observações em campo, os relatos de gerentes e de profissionais evidenciam a existência do que chamamos de mães-babás, mulheres que cuidam em tempo integral dos filhos, enquanto as mães vivem na boate. Estas mães-babás fazem parte da rede de contatos das boates, são vizinhas desse lugar e já estão preparadas para receber as crianças. Assim, a mãe consegue desenvolver a atividade e não perder o contato com os filhos, como aponta Belle de Jour:13

Elas já veem com tudo acertado, elas já veem e perguntam: "posso trazer meu filho?". Eles já concordam, mas dizem que tem que arrumar uma babá pra ficar com ele [o filho], porque não pode ficar ali também, né? [...] Porque elas querem ter o filho perto, por mais que elas deixem com babá, mas elas sabem que eles estão pertinho e que a hora que elas quiserem ir lá ver vão pegar eles pra sair passear, e eles vão saber.

12 Entrevista com Bustuariae, em 14 de junho de 2013, numa rua.

13 Entrevista com Belle de Jour, em 1 de outubro de 2014, numa boate. 
As mães-babás também exercem a maternagem, conforme aponta Badinter (1985) e Longhurst (2008) e mesmo recebendo dinheiro o fato de estarem desenvolvendo maternagens aproxima a babá da mãe. Algumas mães vão ver seus filhos diariamente e outras, aos domingos, os trazem para passar o dia na boate que deixa de ser um espaço de prazer e passa a ser um espaço de exercício de maternagens. As estratégias de maternagens exercidas pelas prostitutas mães em boates são diferentes das que trabalham em bares, mesmo que estejam na modalidade fechada, a boate torna o exercício da maternagem difícil pelo afastamento, entretanto mais fácil pelo não reconhecimento da prostituição por estes.

Os bares em sua maioria têm atividade diurna, tendo relação com o exercício de maternagens, pois permite que muitas mulheres exerçam a atividade enquanto os filhos estão na escola, conforme aponta Séverine:14 "Sempre encaixei [os horários] por causa delas; agora, de vez em quando, também não venho cedo, porque não tem aula pra pequena e a grande saí. Quando ela estava em casa, eu deixava as duas. Agora, a grande vai pro estágio". É comum mudarem de locais ou horários para se adaptar aos filhos e isto é determinante para a fluidez da prostituição. Nos bares noturnos os filhos ficam com as mães durante o dia e com babás ou familiares durante a noite. Muitas mulheres argumentam que o trabalho no bar é mais seguro e é melhor porque se tornam invisíveis aos olhos dos filhos.

Na prostituição da rua as mulheres também trabalham durante o dia enquanto seus filhos estão na escola ou com babás e as que trabalham durante a noite deixam os filhos com vizinhos, familiares ou babás. A diferença é que, na prostituição aberta, a exposição dos corpos é maior e estas mulheres sofrem mais pelo estigma dado a atividade. Ao assumirem o risco de serem vistas pela familia ou filhos, usam estratégias se escondendo nos mesmos hotéis que servem para fazer o programa. Gabriela e Mata Hari argumentam que: "quando a gente vê às vezes algum amiguinho do filho da gente [...] (Mata Hari) a gente tenta correr, a gente se esconde [...] (Gabriela) [...] passando, a gente tenta correr ou a gente não quer se mostrar, aí que tá (Mata Hari). A gente não quer (Gabriela)". ${ }^{15}$

Cada tipo de prostituição contém especificidades em relação às maternagens e a cada experiência espacial interseccional não há como destacar a identidade materna, de prostituta e da classe, pois são vivenciadas de forma simultâneas. Entretanto, a partir dos sistemas de opressão estas mulheres buscam intencionalmente invisibilizar determinada identidade em alguns espaços em detrimento de outras (Valentine, 2007).

Essas experiências em relação à prostituição e às maternagens podem ser vistas na rede discursiva das mulheres prostitutas mães. Levando em consideração as palavras mais citadas nas entrevistas e a conexão discursiva entre elas a partir da intensidade (cor do nó) e da frequência (espessura da aresta) revelam-se estruturas textuais a partir de redes semânticas. ${ }^{16} \mathrm{~A}$ palavra "filhos" foi a mais utilizada nas doze entrevistas, 368 vezes e 2511 ligações com outras palavras evidenciando a importância no exercício de maternagens (Figura 1):17

14 Entrevista com Séverine, em 10 de julho de 2014, num bar.

15 Entrevista com Gabriela e Mata Hari, em 19 de abril de 2014, numa rua.

16 Metodologia baseada no texto de E. Silva e J. Silva (2016).

17 A rede de palavras usadas neste texto corresponde a $4 \%$ da rede geral, porém é a rede que tem o maior grau de interrelação e expressividade no discurso das mulheres prostitutas mães. 


\section{Figura 1 - Rede de frequência e intensidade discursiva das mulheres prostitutas mães na cidade de Ponta Grossa-PR}

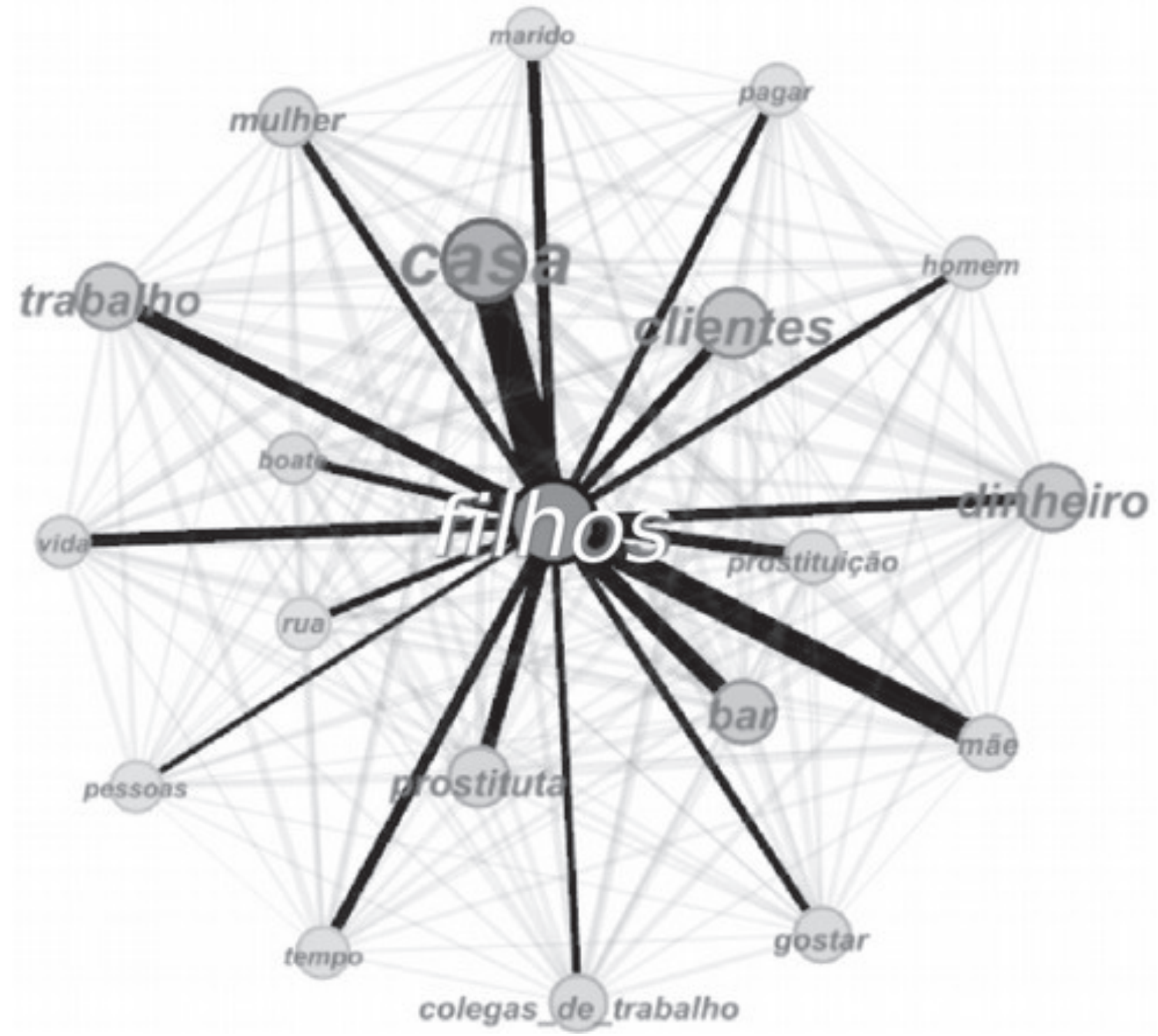

fonte: Entrevistas com mulheres prostitutas mães de Ponta Grossa-PR. organização: As autoras.

Ao destacar a palavra "filhos" percebemos a intensidade discursiva em relação à palavra "casa", ligando maternagem ao espaço privado, assim como a palavra mãe que revela a identidade materna. Entre as palavras mais usadas, a maioria é referente à prostituição como: clientes, trabalho, bar, rua, boate, colegas de trabalho, dinheiro, homem. Além das relacionadas à prostituição outras palavras referem-se ao cuidado dos filhos como: gostar, pagar (as contas), pessoas (ajudam nos cuidados com os filhos), vida (na prostituição), entre outras.

Toda a rede discursiva das mulheres entrevistadas gira em torno dos filhos e da prostituição, sendo impossível destacar a identidade materna da prostituta. A frequência discursiva evidencia que a palavra "filhos" aparece relacionada à palavra bar 52 vezes, enquanto "boate" são 28 vezes e "rua" 24 vezes. Já a palavra "filhos" é utilizada 42 vezes com relação à palavra "prostituta", 40 vezes com "prostituição" e 33 vezes com "cliente". Sendo assim, a relação entre a palavra "filhos", os tipos e a própria prostituição equivale a 59\% do discurso dessa rede discursiva. 
Essa rede discursiva evidencia a centralidade dos filhos e maternagens, em que a prostituição se torna uma forma de cuidado a partir da produção do lar. Se a prostituição é base para o exercício de maternagens não há como destacar o papel da mãe (boa mulher) e da prostituta (má mulher), pois é a má mulher que dá vida a boa mulher segundo as próprias normas de gênero. Entretanto o estigma a atividade, presente $59 \%$ dos questionários, não permite que a própria realidade que tensiona as normas de gênero seja avaliada, fazendo com que estas mulheres joguem com as identidades de mãe e prostituta. A maternidade torna-se uma estratégia, pois usam a gravidez para ganhar mais dinheiro, como aponta Gabriela: "eu trabalhei igual (na gravidez) [...] eu tive axé, sorte assim, nossa! Para o tanto que eu fiquei em casa, deixei minhas contas todas em ordem, guardei um dinheiro pra me manter até a dieta, alguns meses assim, não tenho queixa".

Além da maternidade a própria maternagem torna-se uma estratégia, pois ao jogar com a identidade de mãe conseguem fazer com que o cliente pague mais pelo programa, como evidencia Bustuariae: "muitos homens gostam de conversar, nos perguntam dos filhos, se a gente tem filho, a maioria dos caras conversa e pergunta, e geralmente querem ajudar, eu tenho bastante cliente assim". Na espacialidade da casa estas mulheres jogam com a identidade de prostituta por este ser a forma de sustento, mas também invisibilizam esta identidade para que não sofram preconceito da familia e dos filhos.

Esse jogo interseccional com as identidades de prostituta e de mãe é o que torna a vivência espacial dessas mulheres mais fácil, pois ressaltam ou invisibilizam a identidade materna ou a de prostituta em determinadas espacialidades, tirando proveito dessa intersecção para seu sustento e dos filhos. Sendo a maternagem e a prostituição centrais no discurso dessas mulheres, a partir de estratégias interseccionais, tensiona-se o papel da "boa" mulher, desaparecendo a linha divisória entre o que está dentro e o fora das normas de gênero.

\section{Considerações finais}

A partir da dicotomia homem/mulher se estabelecem padrões do que é ser mulher, criando estigmas àquelas que não se encaixam nos padrões. A prostituição, a partir de práticas sociais ligadas ao casamento, filiação, amor e maternagem, coloca as mulheres prostitutas no limite da normatividade, pois são consideradas dissidentes devido ao comportamento que as afasta do que é considerado normal. Esse afastamento tem estigmatizado as mulheres prostitutas e regulado o corpo das consideradas "boas" mulheres.

Entretanto, a linha que divide a "boa" da "má" mulher se desfaz à medida que há um tensionamento das normas de gênero pelas profissionais do sexo mães, que, ao exercerem a maternagem a partir da prostituição, desafiam a própria norma de gênero a partir do jogo estratégico entre as identidades de prostituta e mãe. Esse jogo está relacionado aos tipos de prostituição, onde a rua, o bar e a boate configuram exercícios de maternagens e estratégias diferentes para ganhar dinheiro e sustentar os filhos.

Esses jogos identitários de prostituta e mãe constituem espacialidades específicas que tensionam as normas de gênero a partir do exercício interseccional dessas identidades e também permitem seu uso interseccional para intensificar o ganho de dinheiro. Nesse sentido, o objetivo deste estudo foi compreender como a interseccionalidade entre maternidade/maternagem e prostituição constituem espacialidades femininas na cidade de Ponta Grossa. 


\section{Referências}

BADINTER, E. O conflito: a mulher e a mãe. São Paulo: Record, 2011.

Um amor conquistado: o mito do amor materno. Tradução de Waltensir Dutra. Rio de Janeiro: Nova Fronteira, 1985.

BUTLER, J. Problemas de gênero. Rio de Janeiro: Civilização Brasileira, 2003.

CATONNÉ, J. P. A sexualidade, ontem e hoje. 2. ed. São Paulo: Cortez, 2001.

CRENSHAW, K. W. Mapping the margins: intersectionality, identity politics, and violence against women of color. Stanford Law Review, v. 43, n. 6, p. 1241-1299, 1991.

DUNCAN, N. Renegotiating Gender and Sexuality in Public and Private Spaces. In:

Bodyspace: Destabilizing Geographies of Gender and Sexuality. New York: Routledge, 1996. p. 127-145.

ENGELS, F. A origem da família da propriedade privada e do Estado. Tradução de Leandro Konder. Rio de Janeiro: Civilização Brasileira, 1982.

HALL, S. A identidade cultural na pós-modernidade. 11. ed. Rio de Janeiro: DPEA, 2011.

HUBBARD, P. Cities and Sexualities. Canada: Routledge, 2012.

Sex and the city: geographies of prostitution in the urban west. Aldershot: Ashgate, 1999.

JOHNSTON, L. Man: Woman. In: CLOKE, P.; JOHNSTON, R. Spaces of Geographical Thought: Deconstructing Human Geography's Binaries. London: SAGE Publications, 2005. p. 119-141.

JULIANO, D. El trabajo sexual en la mira: polémicas y estereotipos. Cadernos Pagu, Campinas, n. 25, p. 79-106, jul./dez. 2005.

Excluidas y marginales: una aproximación antropológica. Madrid: Cátedra, 2004.

LAQUEUR, T. Inventando o sexo: corpo e gênero dos gregos a Freud. Tradução de Vera Whately. Rio de Janeiro: Relume Dumará, 2001.

LONGHURST, R. Maternities: gender, bodies and space. Nova Yourk: Routledge. 2008.

MASSEY, D. B. Pelo espaço: uma nova política da espacialidade. Tradução de Hilda Pareto Maciel, Rogério Haesbaert. Rio de Janeiro: Bertrand Brasil, 2008.

McCALL, L. The Complexity of Intersectionality. Signs - Journal of Women, Culture and Society, Boston, v. 30, n. 3, p. 1771-1800, 2005. doi: 10.1086/426800.

McDOWELL, L. Gender, identity and place: understanding feminist geographies. Minneapolis: University of Minnesota Press, 1999.

MORAES, A. F. Mulheres da vila: prostituição, identidade social e movimento associativo. Petrópolis, RJ: Vozes, 1995. 
PREFEITURA MUNICIPAL DE PONTA GROSSA. Disponível em: http://pontagrossa. pr.gov.br/acidade. Acesso em: 27 jan. 2015.

PULIDO, L. Cummunity, Place, and Identity. In: JONES III, J. P.; NAST, H. J.; ROBERTS, S. M. Thresholds in Feminist Geography: Difference, Methodology, Representation. Boston: Rowman E Littlefield, 1997. p. 11-28.

RAGO, M. Do cabaré ao lar: a utopia da cidade disciplinar - Brasil (1890-1930). Rio de Janeiro: Paz e Terra, 1985.

ROUGEMONT, D. A história do amor no Ocidente. Tradução de Paulo Brandi, Ethel Brandi Cachapuz. 2. ed. reform. São Paulo: Ediouro, 2003.

SCOTT, J. W. Gênero: uma categoria útil de análise histórica. Educação e Realidade, Porto Alegre, v. 20, n. 2, p. 71-99, jul./dez. 1995.

SILVA, E. A.; SILVA, J. M. Ofício, engenho e arte: inspiração e técnica na análise de dados qualitativos. Revista Latino Americana de Geografia e Gênero, v. 7, n. 1, p. 132-154, jan./jul. 2016.

SILVA, J. C. O conceito de território na geografia e a territorialidade da prostituição. In: RIBEIRO, M. A.; OLIVEIRA, R. S. Território sexo e prazer: olhares sobre o fenômeno da prostituição na geografia brasileira. Rio de Janeiro: Gramma, 2011. p. 19-41.

SILVA, J. M. Fazendo geografias: pluriversalidades sobre gênero e sexualidades. In:

(Org.). Geografias subversivas: discursos sobre espaço, gênero e sexualidades. Ponta Grossa: Todapalavra, 2009. p. 25-53.

; SILVA, M. G. S. N. Introduzindo as interseccionalidades como um desafio para a análise espacial no Brasil: em direção às pluriversalidades do saber geográfico. In: SILVA, M. G. S. N.; SILVA, J. M. (Org.). Interseccionalidades. Gênero e Sexualidades na análise espacial. Ponta Grossa: Todapalavra, 2014. p. 17-35.

SILVA, J. M. et al. O corpo como elemento das geografias feministas e queer: um desafio para a análise no Brasil. In: SILVA, J. M.; ORNAT, M. J.; CHIMIN JUNIOR, Al. B. Geografias malditas: corpos, sexualidades e espaços. Ponta Grossa: Todapalavra, 2013. p. 85-142.

VALENTINE, G. Theorizing and researching intersectionality: a challenge for feminist geography. The Professional Geographer, v. 59, n. 1, p. 10-21, 2007. 